UDC: 811.111 '255:34 https://doi.org/10.22190/JTESAP2102193G

Review research paper

\title{
THE BRAND SEMANTICS CULTURAL ADAPTATION STRATEGIES
}

\author{
Olga Glukhova \\ Rostov State University of Economics, Faculty of Linguistics and Journalism, Russia
}

\begin{abstract}
The paper is an interdisciplinary study of brand semantics and the cultural adaptation strategies applied when transferring brand to international or different local markets. The study applies the conceptual approach to brand semantics and aims at outlining the brand semantic cultural adaptation strategies like value-based cultural adaptation and context-based cultural adaptation. The research provides the description of brand semantics in terms of semiotics, cognitive and cultural linguistics proving the brand semantics resemblances to that of cultural concept. The first section deals with brand semantic issues and proposes the method of linguo-cognitive analysis for the brand semantic investigation process. The second section views the brand translation and adaptation approaches in Translation Theories. The last section is devoted to cultural adaptation strategies application to brand constituents when transferring to another culture. Thus, the paper offers a cultural approach to brand translation studies and renders the brand semantics as a series of meanings transmitted by its material (trademark, logo, slogan, advertisement) and non-material (associations, value, uniqueness, inimitable style) constituents that, subjected to linguo-cognitive analysis, enable the application of contextbased or value -based cultural adaptation strategy.
\end{abstract}

Key words: adaptation, translation, culture, brand, semantics

\section{INTRODUCTION}

The problem of brand translation and cultural adaptation is the subject matter of both General and Specific Translation Theories. The brand semantics is a new field of interdisciplinary study that uses the data of linguistics, marketing, psychology, cognitive science and cultural linguistics. The brand semantics is considered to be of great current interest due to the global marketing processes that enable thousands of companies to represent their brands (goods and services) into the international and local markets that are different linguo-cultural environments.

The majority of language-based research deal with brand in the field of Translation theories offering the translation methods (Dong et al. 2001), linguistic strategies for brand translation based on aim-adaptation (Jiafeng Liu 2017, Hong et all 2002) or pragmatic (Stadulskaya 2014) approach. Though there are some studies that tend to investigate the

Submitted December $24^{\text {th }}, 2020$, accepted for publication March $13^{\text {th }}, 2021$

Corresponding author: Olga Glukhova. Rostov State University of Economics, Faculty of Linguistics and Journalism, Bolshaya Sadovaya, 69, Rostovskaya oblast, 344002, Russia|E-mail: olga_glukhova_@mail.ru 
«semantic space» of the phenomenon from the psychological (Alexandrova 2017), social (Ovrutskiy 2011) and cultural (Evsyukova et al 2018) point of view. The brand studies in terms of cultural and cognitive fields are few and lack the academic basis.

The paper offers a relevant research of theoretical ground for brand cultural and conceptual studies rendering brand as a series of meanings, notions, ideas and associations in the consumer's mind (that assimilates brand and cultural concept). As far as every culture conveys all mentioned above phenomena in its own way the brand semantic structure decoding process sometimes appears to be unsuccessful. The problem of brand translation and adaptation is to find the means of adequate culture-based translation with meaning significance special attention to all brand constituents.

The aim of the study is to outline the brand semantic cultural adaptation strategies like value-based cultural adaptation and context-based cultural adaptation.

The main method of the study is linguo-cognitive analysis that enables to investigate the brand inner form via the semantic structure that is transmitted by brand material (trademark, logo, slogan, advertisement) and non-material constituents (associations, value, uniqueness, inimitable style).

The main objectives of the paper are: to give the brand semantic studies analysis in different fields of knowledge; to provide an outlook of brand translation and adaptation strategies in linguistics; to describe and analyze the application of cultural adaptation strategies to a number of global brands.

\section{BRAND SEMANTICS STUdiES ANALYSIS}

Brand semantic studies date back to marketing (Verkman 1986, Barns 2003, Cherchill 2007), linguistics (Stadulskaya 2014, Evsyukova, Glukhova 2011) and translation sphere (Pym 2004) of the past four decades that evaluate the problem of brand semantics in terms of brand name denotative and connotative components.

Nowadays the brand semantics as a complex and sophisticated interdisciplinary notion has become a subject of different investigation fields like psychology (Alexandrova 2017), linguistics (Buler 1993), social communication theory (Ovrutskiy 2011), philosophy (Shmigin 2009), cultural linguistics (Evsyukova, Glukhova 2011, Evsyukova et all 2018). It would be fair to say that every discipline defines brand semantics in its own way, taking into consideration various features of the phenomenon.

As soon as there are still not so many linguistic studies of brand semantics we aim at giving the essential definition for the needs of linguistic, cultural and translational research. For that purpose, the following passages outline the brand semantics view in areas of knowledge mentioned above and provide the basis for cultural and conceptual approach to brand semantic studies.

\subsection{The symbolic approach to brand semantics}

As symbol is one of the notions studied by cultural linguistics the symbolic approach appears to be relevant for the present research. The symbolic approach tend to refer brands as set of images, semiotic system based on symbols. According to A. Ovrutskiy brands are similar to images in "discursiveness, mosaic structure, atomicity, distancing from the author, heroic character (the product as the hero of brand" (Ovrutskiy 2011). The scientist describes some particular brand features like "universal character of brand's 
meaning perception". This feature turns out to be quite a disputable one. The experiment held in one of our previous studies showed significant differences in verbal trademark (a material constituent of brand) perception depending on social, cultural and linguocultural identity parameters (Glukhova, Evsyukova 2019). The second feature called "high impact potential" depends greatly on linguocultural environment. The third point is it's "semantics social capacity", which is sometimes very close to a cultural capacity. The next point deals with goods' quality symbolization, meaning identification and image projection potential. A. Ovrutskiy states that brand possesses a number of signs organized in layers, some resources for social involvement (that deals with needs and their satisfaction) and social cognition.

The author points out the resemblance between brand and archetype. But the most noticeable idea of A. Ovrutskyi in terms of the article is rendering brands as semiotic system or a sign language with syntax, semantics and pragmatics as general constituents. The author sees the brand syntax in its metaphorical or metonymical organization explicated in both verbal and visual elements (Ovrutskiy 2011). The brand pragmatics, according to A. Ovrutskiy, is realized by means of either brand identification or brand projection. The identification here is human consciousness equaling to the external image (brand), leading to special behavior models appearance. The projection is the opposite process that grants the features of internal psychological phenomena to the external images.

The brand syntax according to Ovrutskiy reveals in metaphorical and metonymical organization of brand denotative structure. As to the brand semantics, the author denotes it via social meanings like gender, age, social values, political preferences (Ovrutskiy 2011). The most essential for the present study is social value meaning speculation as it implies the axiological vector.

\subsection{The psychological approach to brand semantics studies}

The psychological approach deals with brand semantics in terms of perception. Irina Alekdandrova offers a unique description of a brand semantic space (Aleksandrova 2017) based on the meaning definition given by Lontyev who renders it as "generalised reflection of reality that has become the property of my consciousness, developed by mankind and fixed in the form of concept, knowledge and even skill as a generalised way of action" (Cit. by Aleksandrova 2017). Hence, the semantic space of the brand is a system of its subjectively significant features formed in the mind of the consumer, determining the specifics of brand perception and acting as an operational model of cognitive structure of consumer's individual consciousness. This definition comes close to the ideas of concept in linguistics and cognitive science.

The author points out that brand image in consumers' mind differs greatly from the brand image implied by the creator. The idea has already been elaborated in our previous paper dealing with cultural differences in brand perception (Evsyukova, Glukhova 2020).

\subsection{The brand semantics in linguistic studies}

The present brand studies in linguistics render them mainly as semiotic system. Some brand constituents like verbal trademarks were elaborated in works of N. A. Stadulskaya (the semiotic and pragmatic view) (Stadulskaya 2014) and O. Glukhova, T. Evsyukova (the linguocultural aspect) (Evsyukova, Glukhova 2011). L. Fedorova (Fedorova 2019) holds a semiotic analysis of such brand constituents as slogans and credit them with three main functions of any sign: identification, regulation and modeling. In K. Buler terminology sign 
function are symptoms, signals and sygnals (Buler 1993). The semiotic model correlates the brand and the two aspects of sign: the denotatum (the product or service) and significatum (the image capable of having impact on buyer.

\subsubsection{The brand connotations}

The connotative meaning of a brand contains suggestion or association of various nature (phonetic, cultural, religious etc.). The framework of the paper provides the cultural connotations issues.

The study is based on the idea of cultural connotations being the semantic components that embody the material and spiritual culture specific features of a particular linguocultural community. This is a heterogeneous semantic component that grounds such generalized semes like "ethnicity", "locality", "historical attribution", "socio-political activity", "sociocultural information", "confessional affiliation". The brand constituents that realize the above mentioned semes are considered to be culturally significant. Thus, trademarks contain various types of toponyms related to national and cultural information.

The use of geographical names makes it possible to transfer the figurative motifs inherent in the area itself to the idea of products. Let us consider some examples: NOKIA - a telecommunications company, from Nokia - a city located in Finland on the banks of the Nokianvirta River; WINSTON is a brand of cigarettes from Winston - Salem - a city in the state of Carolina, a historical center for the commodity sheet processing etc.

Cultural and historical connotations are of great value in the structure of the brand meaning and reflect the referent lifetime in a particular national and cultural community. Here are some examples of brands exploiting the names of well-known people: TUDOR a trademark in mechanical engineering, associated with the English Tudor dynasty; ERMAK - mayonnaise associated with the Russian national hero.

Some brands use the national ideas conveyed with the help of modern expressive means". This gives them a special national flavor and compares favorably with the goods of other countries of the world. For example, the English language environment is characterized by the following realities: WHITEHALL - a street in the center of London, and the record trademark; BIG BEN - a famous tower clock that has become a symbol of the city (a trademark of smoking pipes). For Russian culture, the following examples of national culture realities are: RUSSIA TROIKA - chocolate, associated with the traditional team of three horses - a symbol of Russia; TSAR-PUSHKA - beer, reminiscent of the national heritage, etc.

The cultural connotations in the brand semantic structure realize the connection with the national culture and appeal to the most significant phenomena of ethnic value system.

\subsubsection{The brand semantics in cultural linguistics}

As long as there is still no any sufficient linguistic definition of brand semantics and it is essential in terms of choosing translation and adaptation strategies we bare to offer some speculations on the phenomenon.

Taking into consideration the data of sociology and psychology that render brands as images in consumer's mind we come close to the idea of cultural concept.

The concept according to Slyshkin G.G. is a "conventional mental unit aimed at comprehensive study of language, consciousness and culture" (Slyshkin 2004). Brand, as it was stated earlier, is a series of meanings, notions, ideas and associations in the consumer's mind. To present the argument for the idea of brand similarity to concept let us consider the 
concept structure. Slyshkin G.G. outlines the most important features of linguocultural concepts that we introduce to brands.

1. The complex character of existence. It is simultaneously presented consciousness, culture and language. As for the brand it also has different manifestations: verbal, mental and cultural (cultural differences in perception for example).

2. The mental origin of the concept. The concept is located in consciousness thus making any investigation of concept to be a cognitive in its nature. The brand semantics studies seem to be similar to that of cognitive analysis.

3. The concept is limited by the member consciousness. "Any elements of the concept missing in the person or group consciousness do not implicate the conceptual structure of a person or a group" (Evsyukova, Butenko 201)].

4. The value character of concept. Every linguocultural concept foregrounds some cultural value. The value is the core of the concept. Brands like concepts bare values, transmit them and are capable of forming new ones (Evsyukova et al. 2018).

5. The conventional character and indistinctness of concept. Brands are also conventional units and all the constituents' meanings intermingle and intersect. Brands as well as concepts are indistinctive in human consciousness. They have a core (a product or a service) and different associative vectors. The most person's significant associations build up the core of the brand for a particular consumer, the less significant - its edge.

6. Polyappealing character. The concepts like brands become active in people's minds by means of associations according to "stimulus-reaction" model. The brand image can be "switched on" by different stimulus like word, visual image, picture, sound, smell, surface etc. The conceptual analysis of brand semantics implies the investigation of such stimuli (in other terms signs) semantics.

All stated above leads us to the idea of linguo-conceptual analysis appliance to the subject study.

\subsubsection{The linguo-cognitive analysis in brand semantics studies.}

The method of linguo-cognitive analysis is the main tool of cognitive linguistics and deals with concepts by means of two types of approach: "from meaning to language", where a certain concept of culture appears as meaning, and «language» is all possible ways of concept verbalization; "From language to meaning" (semantic-cognitive), where a key linguistic unit (word, phrase, paremia) is taken as a starting point and examined for the presence of special semantic features that actualize a "clot of meaning" - a concept (Evsyukova et al. 2020, 113).

The linguo-cognitive analysis of brand semantics implies the both types of procedures. The first way of brand image decoding is used by a creator, who aims to some value and seeks the means verbalizing it in order to make the product or service attractive. The second procedure is used unconsciously by a consumer when bringing brand signs (verbal and nonverbal) into correlation with his own value system.

But when it comes to the translation and adaptation issues of brand both procedures take place one after another. 


\section{BRAND TRANSLATION AND ADAPTATION STRATEGIES IN LINGUISTICS}

\subsection{Adaptation studies in Translation Theories}

The question of translation and adaptation differentiation is quite a disputable one in nowadays humanities. The traditional science renders Translation as the process (and its result) of accurately rendering the meaning of a verbal expression in natural language 1 in a different natural language 2. Adaptation is considered to be a process that draws attention to its reproductive act and is often understood as free translation (Cattrysse 2018).

In terms of semasiology R. Jacobson differentiates intra-lingual and inter-semiotic translation and the last one is described as transfer from one semiotic system to another (Jacobson 2000). Back to our previous notions of brands being a semiotic system the adaptation appears to be the most effective strategy in exporting brands across the markets.

The Dictionary of translation studies defines adaptation as "any target text in which a particularly (free) translation strategy has been adopted". The adaptation deals with phenomena that do not exist in a target culture and that need much rewording" (Shuttleworth $\&$ Cowie 1997). All stated above leads to the appearance of different adaptation approaches that are to be discussed further.

Garbovskiy N.K defines adaptation as «one of the semantic translation techniques and is used in translation theory to denote such type of transformation that results not only in a particular objective situation description change, but the replacement of the very objective situation» (Garbovsky 2004: 406). The positive property of this technique - to make it easier for the translated text recipient to understand the original meanings.

\subsection{Brands' adaptation strategies}

The recent-year Theory of translation witnesses the appearance of new approaches to the translation process like aim-adaptation approach (Lisha Zeng 2014, Jiafeng Liu 2017) and localization (Pym, 2004, Evsyukova, Glukhova 2019) and cultural adaptation suggested in this paper.

The aim-adaptation approach implies the "aim-needs of the clients and the targeted customers as decisive factors, making the translator select part of the intended information in the original text or create new meaning desired by the clients and the targeted customers in the translated version". The author proves his ideas outlining adaptability as «the property of language which enables human beings to make negotiable linguistic choices from a variable range of possibilities in such a way as to approach points of satisfaction for communicative needs» (Jiafeng Liu 2017).

Jiafeng Liu investigates the pragmatic issues of brand names translation and considers that the «meanings the brand has to convey in the translated name may completely differ from those the original brand name does. As a result, the translating of brands is not a simple decoding and encoding process but a linguistic adaptation of the aim-needs of the clients and the targeted consumers» (Jiafeng Liu 2017). Among all strategies of aimadaptation approach used for brand-name translation he mentions phonetic, lexical and semantical adaptation.

Mohsine Khazrouni also insists on the importance of target audience translation as extralinguistic factor especially dealing with cultural or religious themes (Khazrouni 2017).

Thus, adaptation turns out to be the most preferable technique of brand rendering into another language, since the differences in the original value system and the receiving one 
can be extremely significant, making brand semantic structure be a translator of alien meanings, cause the opposite pragmatic effect and make the brand unattractive.

\subsubsection{Brands' cultural adaptation approach}

According to L. Chan "adaptations are like domesticated translations, where target values, conventions and norms are superimposed on the source text, cultural differences are erased and the foreign becomes palatable for the local audience" (Chan 2012). The cultural adaptation implies the adaptation of a brand by means of certain procedures to an extremely adequate, «completely corresponding, coinciding, identical»(Garbovsky, 2004: 489) by another culture reader perception.

The cultural adaptation approach used in the research is based on the data of cognitive translation studies (Shreve 2016, 141) that deal with information «processing stages» like comprehension, transfer and production, corresponding to the processes of brand semantic structure linguo-cognitive analysis procedures stated above.

The linguo-cognitive analysis suggests the brand semantic elements conceptual, value and cultural context consideration that leads to the appearance of some basic cultural adaptation strategies.

\section{BRAND CULTURAL ADAPTATION STRATEGIES APPLICATION}

\subsection{The context-based brand adaptation strategy}

The contextual adaptation is based on the idea of common knowledge among one culture representatives. This knowledge plays the role of a context, which may not correspond to another culture context in terms of content and capacity. The context manifests in all the constituents of brand semantic structure: visual image, advertising, slogan, trademark. Thus, the package indication "Does not contain GMOs" can have completely different effects on the consumer in different cultures. The European market renders this brand element as a successful, "selling" one, in Russia it was not significant until recent times, as for the developing countries of Africa, in the face of food shortages, the presence or absence of GMOs neither makes difference nor contributes to the brand pragmatic function implementation. Thus, the socio-economic or historical-cultural context, as well as the prevalence of certain concepts, ideas or values, turns out to be decisive when choosing a strategy for brand adaptation in the host culture.

According to G. Hofstede, "the content and the scope of knowledge differs from one culture representative to another" (Hofstede, 2015, 11). The author claims the knowledge content depends on culture basic axiological attitudes like individualism or collectivism and suggests using simplified ("without hints") text versions in individualist cultures, and polysemantic texts with a wide range of associations in collectivist cultures.

The current concepts that activate context layer also differ from country to country. Thus, the cholesterol level issues are important in Russia because it causes cardiovascular system diseases - the first and state level of the discussed cause of death in the country. The product with a low-level cholesterol indicator becomes a key hook in Russian market. Sergey Vykhodtsev, the founder of the Bystrov brand, for example, is building the positioning and advertising campaign of his products on the use of fiber contained in soy (Vitaven) - a panacea for cholesterol1. In United States, where the problem of 
cholesterol is not so popularized, the key word is "calorie" and vitamin content. For example, Kraft Foods' Tang Fruitrition brand is advertised in the US as containing vitamin $\mathrm{E}$, in the Philippines as a source of iron.

The next example is the iWatch slogan by Apple "You. At a glance. " The slogan was interpreted in Russian as follows - "Скажут о тебе все и сразу» (They will say everything about you at once). This interpretation of the slogan was unfortunate in Russia. The fact is that shortly before the release of the Apple watch in Russia, the Yarovaya package was released. It contains two bills, one of which obliges to store information about all negotiations that are conducted by means of network and telephone. These bills caused a flurry of negative comments. Moreover, people began to worry about their "virtual life" security. Also, this slogan is associated with the phrase of the Russian writer Mikhail Zhvanetsky: "Usually you want everything at once, but you get nothing gradually." This statement means that it takes effort to achieve goals, but some people are lazy and impatient because they want instant results. The fear for one's "virtual life" in conjunction with this statement had an extremely negative connotation. Apple did not consider these facts when implementing the product. The product could not fully adapt and localize. It was this slogan that contributed to the low sale and distribution of new watches on the Russian market.

\subsection{The value-based brand adaptation strategy}

The of value-based brand adaptation strategy implies the set of basic culture values analysis and the target group set of value attitudes (as even within the same culture there may exist subcultures with an extremely polar worldview), a set of concepts that appeal to certain values, concepts verbalization means, associative fields of linguistic units that actualize the identified concepts.

The brand values may not always suit the taste of another culture representatives. In value-based adaptation process we should take into account such culture characteristics like: the hierarchy of society, democratic relations in society and in the family (Hofstede 2015: 23).

Let us see some examples. The EA Sports computer games manufacturer sells the products in the US market under the slogan "Challenge Everything". When the advertisement was transferred to the Eastern Europe countries with a high level of hierarchy and non-conflict orientation, the slogan caused a lot of protests.

The other example is one of McDonald's slogans: "We love to see you smile". The slogan, when adapted for the Russian market, was translated by tracing. But, in the end, it tuned up to be imperceivable in Russia, that is, the slogan failed to successfully localize. This problem is related to the mentality peculiarity. The fact is that Russians smile in public very rarely, compared to people from other countries like England, United States, Spain, etc. That is, a smile is a national feature of these countries. This feature became an adaptation error. Therefore, in this case, the tracing method turned out to be an unsuccessful strategy for the successful Russian market localization.

The slogan of the American company Burger King "You're the boss" - which in Russian reads as follows - "Ты здесь главный" (You are in charge here) is a good example of valuebased adaptation. An equivalent translation was used in Russian translation. The word "boss" is not perceived in Russian culture as someone in charge and has some negative connotation, so it is not preferable. Consequently, the word was replaced during translation. Dahl's Explanatory Dictionary of the Russian Language gives the following definitions with the 
word "главный": 1. Basic, most important; 2. Senior in rank; 3. Leading something. That is why, when translating into Russian, an acceptable word for Russian culture was chosen. This product continues to gain popularity in Russia among people of any gender and age.

The slogan "Love London Style" by British cosmetics brand Rimmel London is another example. The slogan is translated into Russian as "London Style". This translation, point at the propensity to borrow as the feature of Russian culture acquired over time. The very openness to everything foreign in the Russian mind is a value. Ever since the time of Peter the Great, Russia began to import European clothing and technology, adopted a way of life and ideology. "Peter the Great took state forces, supreme power, law, estates from old Russia, and borrowed technical means from the West for the organization of the army, navy, state and national economy, and government institutions," wrote Russian historian Vasily Klyuchevsky in the beginning of 20th century. Until now, there is an opinion in Russia that "foreign means the best". Moreover, nowadays there is a widespread "hipster" style of London among young people, which is shown by models in Rimmel's advertisements. This slogan is also aimed at the overwhelming number of buyers of this product, that is, young people. Using an associative dictionary, you can find out that one of the main associations with the word "style" is the adjective "youth". That is, this slogan, aimed at the younger generation, evokes native associations and thereby "incites" them to make a purchase. This strategy was the right decision and that is why this cosmetic company is successful in the Russian market.

\section{CONCLUSION}

The problems discussed in the paper deal with the global phenomenon of brand and correspond to the modern trends of interdisciplinarity in humanitarian knowledge. Despite the great number of brand translation strategies studies there can still be seen some challenges when locating in different cultures. The study exploits the cultural approach and renders the brand semantic structure as a series of meanings transmitted by its material (trademark, logo, slogan, advertisement) and non-material constituents (associations, value, uniqueness, inimitable style), which could be studied by means of linguo-cognitive analysis.

The basis for the stated ideas lies in a complex brand semantics character that turns out to be a sophisticated interdisciplinary notion and has become a subject of different investigation fields like psychology, linguistics, sociology, philosophy. The study of brand semantics social, psychological and linguistic observation rendering it as set of images, a system of its subjectively significant features formed in the mind of the consumer or semiotic system correspondingly supports the conceptual view of brand semantics. The characteristic features of concept like complex character of existence, the mental origin, the value character, polyappealing character and others match those of brands and enable the linguo-cognitive analysis. The linguo-cognitive analysis suggests the brand semantic elements conceptual, value and cultural context consideration that leads to the appearance of some basic cultural adaptation strategies

The contextual adaptation is based on the idea of common knowledge among the culture representatives. The of value-based brand adaptation strategy implies the set of basic culture values analysis and the target group set of value attitudes, a set of concepts that appeal to certain values, concepts verbalization means, associative fields of linguistic units that actualize the identified concepts. The importance of culture-oriented approach is illustrated by brand name adaptation examples and leads to more profound studies of the subject. 


\section{REFERENCES}

Alexandrova Irina Y. Research of the semantic space of the brand // Vestnik GUU. (2017) No. 1. URL: https://cyberleninka.ru/article/n/issledovanie-semanticheskogo-prostranstvabrenda (date accessed: 11/10/2020).

Barnes B., Schultz D. Strategic brand communication campaigns. M., 2003.

Buhler K. Model of language as an organ // Buhler K. Language theory. M.: Progress, (1993) p. 30-36.

Chan, Leo. A Survey of the 'new' discipline of adaptation studies: between translation and interculturalism. Perspectives 2012 20.4:411-418. Doi:10.1080/0907676X/2012/726232

Churchill, G. Marketing research / G. Churchill, T. Brown. - SPb. : Peter, 2007 .- 704 p. ISBN 978-5-469-01132-3.

Garbovsky N.K. Translation theory. M .: Publishing house of Moscow. University 2004. $-544 \mathrm{p}$.

Glukhova, O. Evsyukova, T. Linguocultural identity aspects in the process of verbal trademarks perception and translation. The journal of teaching English for specific purposes. (2019) Vol. 7, № 4. pp. 483-491

Dong, L. C., \& Helms, M. M. (2001). Brand Name Translation Model- A Case Analysis of US Brands in China. Journal of Brand Management, 9(2), 99-115.

Evsyukova T.V. \& Barabanova I.G. \& Glukhova O.V. \& Kotelnikova E.V. "The Foreign Language Trademarks and Axiological Code Transformation Under the Host Culture Influence," European Research Studies Journal, European Research Studies Journal, (2018). vol. 0 (Special 2), pages 678-689.

Evsyukova T.V. Butenko E. Yu. Linguoculturology: textbook / M.: FLINT: Nauka - (2014) $480 \mathrm{p}$.

Evsyukova, T., Glukhova, O. Verbal trademarks: the onomastic and cultural linguistics aspects. Rostov State Economic University (2011).

Evsyukova T.V. \& Glukhova O.V. \& Kazanskaya E.V. The reasoning for quantitative and linguo-cognitive analysis of Russian-speaking linguistic personality cultural value dictionary. Graduate School: Research. Materials of the Interuniversity International Congress (2020) (Moscow, November 12, 2020).

Fedorova L. L. Semiotics of advertising: functional and communicative analysis // Vestnik NSU. Series: History, Philology. (2019). Vol. 18, No 6: Journalism. S. 199-211. DOI 10.25205 / 1818-7919-2019-18-6-199-211

Gambier, Yves and Luc van Doorslaer, editors. Crossing Borders. Translation Studies and Other Disciplines. Amsterdam, Netherlands: John Benjamins, 2016.

Hofstede G.H. Cultures and organizations: software of the mind. Mc Graw Hill. - 2010. 279 https://globalsociology.ucoz.ru/_ld/0/2_CulturesandOrga.pdf

Hong, F. C., Pecotich, A., \& Schultz, C. J. (2002). Brand Name Translation: Language constraints, product attributes, and Consumer Perceptions in East and Southeast Asia. Journal of International Marketing, 10(2), 29-45.

Jakobson, Roman. On linguistic aspects of translation. In The Translation Studies Reader, Lawrence Venutti (ed), 2000 (1959). 113-118. London \& New York: Routledge

Jiafeng Liu Linguistic Strategies for Western Cosmetic Brand Translation in China International Journal of Business and Management; (2017) Vol. 12, No. 11; 2017 ISSN 1833-3850 E-ISSN 1833-8119 Published by Canadian Center of Science and Education URL: https://doi.org/10.5539/ijbm.v12n11p164 
Mohsine Khazrouni Adaptation in Translation: Howells's Short Story “Christmas Every Day" AWEJ for Translation \& Literary Studies (2017) Volume, 1 Number 3, August 2017 Pp. 237-251 DOI: http://dx.doi.org/10.24093/awejtls/vol1no3.15

Ovrutskiy A.V. Brand as a sign-social system / A. V. Ovrutskiy // Philosophy of Social Communications. - No 4 (17). (2011). pp. 19-25.

Patrick Cattrysse Adaptation Studies, Translation Studies, and Interdisciplinarity. Reflections on Siblings and Family Resemblance Adaptation (2018)Vol. 12, No. 3, pp. 206-221 doi:10.1093/adaptation/apy011 Advance Access publication September 24, 2018

Petrenko, V.F. Psychosemantics of consciousness / V.F.Petrenko. - M.: Book on demand. (2012) 208 p. - ISBN 978-5-458-27014-4

Pym, Anthony. Localization from the Perspective of Translation Studies: Overlaps in the Digital Divide? (2004) . https://www.researchgate.net/profile/Anthony_Pym2

Shmigin, I. Philosophy of consumption: per. from English / I. Shmigin. - Kharkov: Humanitarian Center, 2009.

Shreve, Gregory M \& Diamond Bruce J. Cognitive neurosciences and cognitive translation studies. About the information processing paradigm. Crossing Borders. Translation Studies and Other Disciplines. Amsterdam, Netherlands: John Benjamins, 2016.

Shuttleworth, Mark and Cowie, Moira. Dictionary of Translation Studies. Manchester: St. Jerome. 1997

Slyshkin G.G. Linguocultural concepts and meta-concepts. - Volgograd: Peremena. (2004)

Stadulskaya N.A. Trademarks in the language and non-linguistic reality of the United Kingdom and the United States. The dissertation of the scientific degree of Doctor of Philology. Pyatigorsk. (2014)

Verkman J K Trademarks: creation, psychology of perception. M., 1986

Zeng, L. S. A Systematically Integrated Study of Translatology. Foreign Language Teaching and Research Press. (2014) 